\title{
Differential response of plant water consumption to rainwater uptake for dominant tree species in the semiarid Loess Plateau
}

\author{
Yakun Tang ${ }^{1}$, Lina Wang ${ }^{1}$, Yongqiang Yu ${ }^{1}$, Dongxu Lu ${ }^{1,2}$ \\ 5 \\ ${ }^{1}$ State Key Laboratory of Soil Erosion and Dryland Farming on the Loess Plateau, Institute of Soil and \\ Water Conservation, Northwest A\&F University, Yangling, 712100, China \\ ${ }^{2}$ State Key Laboratory of Soil Erosion and Dryland Farming on the Loess Plateau, Institute of Soil and \\ Water Conservation, Chinese Academy of Sciences, Ministry of Water Resources, Yangling, 712100, \\ China
}

Correspondence to: Yakun Tang (t453500@163.com)

Abstract Whether uptake of rainwater can increase plant water consumption in response to rainfall pulses requires investigation to evaluate the plant adaptability, especially in water limited regions where rainwater is the only replenishable soil water source. In this study, the water sources from rainwater and three soil layers, predawn $\left(\Psi_{\mathrm{pd}}\right)$, midday $\left(\Psi_{\mathrm{m}}\right)$ and gradient $\left(\Psi_{\mathrm{pd}}-\Psi_{\mathrm{m}}\right)$ of leaf water potential, and water consumption in response to rainfall pulses were analyzed for two dominant tree species, Hippophae rhamnoides and Populus davidiana, in pure and mixed plantations during the growing period (JuneSeptember). In pure plantations, the relative response of daily normalized sap flow $\left(\mathrm{SF}_{\mathrm{R}}\right)$ was significantly affected by rainwater uptake proportion (RUP) and $\Psi_{\mathrm{pd}}-\Psi_{\mathrm{m}}$ for H. rhamnoides, and was only significantly influenced by $\Psi_{\mathrm{pd}}-\Psi_{\mathrm{m}}$ for $P$. davidiana $(\mathrm{P}<0.05)$. Meanwhile, the large $\Psi_{\mathrm{pd}}-\Psi_{\mathrm{m}}$ was consistent with high $\mathrm{SF}_{\mathrm{R}}$ for $H$. rhamnoides, and the small $\Psi_{\mathrm{pd}}-\Psi_{\mathrm{m}}$ was consistent with the low $\mathrm{SF}_{\mathrm{R}}$ for P. davidiana, in response to rainfall pulses. Therefore, H. rhamnoides and P. davidiana exhibited sensitive and insensitive responses to rainfall pulses, respectively. Furthermore, mixed afforestation significantly enhanced RUP, $\mathrm{SF}_{\mathrm{R}}$, and reduced the water source proportion from the deep soil layer 
$(100-200 \mathrm{~cm})$ for both species $(\mathrm{P}<0.05)$. The $\mathrm{SF}_{\mathrm{R}}$ was significantly influenced by $\mathrm{RUP}$ and $\Psi_{\mathrm{pd}}-\Psi_{\mathrm{m}}$ for both species in the mixed plantation. Lower $\Psi_{\mathrm{m}}$ and higher $\Psi_{\mathrm{pd}}$ were adopted by $H$. rhamnoides and $P$. davidiana in mixed plantation, respectively, to enlarge $\Psi_{\mathrm{pd}}-\Psi_{\mathrm{m}}$, enhance rainwater uptake, and decrease water source competition from the deep soil layer. These results indicate that mixed afforestation enhanced the influence of rainwater uptake to water consumption after rainfall pulse, regardless of sensitivity to rainfall pulses. This study provides insights into suitable plantation species selection and management considering the link between rainwater uptake and consumption in water limited regions.

35 Keywords: Leaf water potential; Loess Plateau; Plant water consumption; Rainwater uptake; Water stable isotope

\section{Introduction}

Rainwater uptake by plant and water consumption in response to rainfall pulses drive the survival of plant species and ecosystem ecohydrological processes, especially in arid and semiarid regions where rainwater is the only replenishable soil water source (Berkelhammer et al., 2020; Gebauer and Ehleringer, 2000; West et al., 2012). Generally, rainwater uptake is refers to the uptake of rainwater by plant roots, and plant water consumption is refers to the absorbed water transported to leaves through stems for transpiration, and can be quantified through water stable isotope and thermal dissipation methods, respectively (Meier et al., 2018; Tfwala et al., 2019; Zhang et al., 2019). The variability and intermittency of rainfall, which plays an important role in plant water uptake and consumption (Swaffer et al., 2014; Wang et al., 2020), have been predicted to increase in water limited regions (Klein et al., 2014; Mendham et al., 2011). Clarifying the influence of rainwater uptake to plant water consumption after rainfall pulses is essential to understand the process of plant species adaptation in water limited regions (Meier et al., 2018; Tfwala et al., 2019).

Rainwater uptake by plant is expected to increase water consumption after a rainfall pulse (Cheng et al., 2006; Liu et al., 2019; Xu et al., 2012). However, the uptake of rainwater may also be mainly used to reduce the water uptake from deep soil layers or decrease the risk of cavitation in stems for some 
plant species (Plaut et al., 2013; Tfwala et al., 2019). The controversial rainfall pulse response between water uptake and consumption may be mainly attributed to an inconsistent influence of plant leaf physiological characteristics (West et al., 2007), root morphology adjustment (Wang et al., 2020), or environmental conditions (Tfwala et al., 2019) on these two water processes. Generally, water consumption is observed to increase after rainfall pulses for plants with shallow (Liu et al., 2019) or dimorphic root systems (Swaffer et al., 2014); meanwhile, no increase or a decrease in water consumption is observed for plants with deep rooting systems (West et al., 2012). However, regardless of the root distribution, the plant leaf water potential gradient (the difference between predawn $\left(\Psi_{\mathrm{pd}}\right)$ and midday $\left(\Psi_{\mathrm{m}}\right)$ leaf water potential) has been observed to regulate water consumption after rainfall pulses (De Guzman et al., 2016; Liu et al., 2019). Thus, taking into consideration plant leaf physiological or root morphological parameters could help in understanding the mechanisms underlying the influence of rainwater uptake on plant water consumption in response to rainfall pulses.

Uptaking contrasting water sources between coexisting species usually shows water source separation and can minimize water source competition (Munoz-Villers et al., 2020; Silvertown et al., 2015); however, overlapping water sources among plant species may lead to competition in arid and semiarid regions (Tang et al., 2019; Yang et al., 2020). Rainfall pulses have been observed to relieve or eliminate water competition and thus maintain or increase plant water consumption in some water limited regions (Du et al., 2011; Tfwala et al., 2019). Meanwhile, plant species with strong rainwater uptake ability generally exhibit more competitiveness than coexisting weak rainwater uptake ability species (Stahl et al., 2013; West et al., 2012). However, Liu et al. (2019) attribute opposite rainwater uptake ability to the stable coexistence of species in mixed plantations in semiarid regions, where the rainfall events are variable and less rainwater is uptake by one of the coexisting plant species. In addition, coexisting species may also cope with or minimize water resource competition through plant leaf water potential or root distribution adjustment (Chen et al., 2015; Silvertown et al., 2015). It is still unclear whether these adjustments could influence the rainwater uptake and water consumption for coexisting species in water limited regions.

The "Grain for Green project" has increased vegetation coverage by $25 \%$ in the Loess Plateau 
through afforestation activities since the 1990s, to deal with vegetation degradation and water and soil loss (Tang et al., 2019; Wu et al., 2021). Hippophae rhamnoides and Populus davidiana are typical dominant tree species, with high survival rate and drought tolerance, and occupy nearly $30 \%$ of the plantation area in this region (Liu et al., 2017; Tang et al., 2019). In addition to $H$. rhamnoides and $P$. davidiana pure plantations, mixed plantations of these two species were also widely promoted due to the higher soil and water conservation capacity than pure plantations in the original afforestation stage (Tang et al., 2019; Wang et al., 2020). Rainwater has obvious seasonal variability and is the only replenished soil water source in this region because of the soil is approximately $100 \mathrm{~m}$ deep (Li et al., 2016; Zhang et al., 2017). The imbalance between rainwater input and plant water demand may weaken the sustainability of plantations with further plant growth (Jia et al., 2020; Wu et al., 2021). Previous investigations in the region quantified the water sources from different soil depths (Wang et al., 2020; Wu et al., 2021) and characterized the water consumption (Zhang et al., 2017) during drought stress periods for plantation species in pure plantations. To understand the adaptation of plantation species in this study, the water consumption, water sources from rainwater and different soil layers, and plant leaf water potential for $H$. rhamnoides and $P$. davidiana in pure and mixed plantations were analyzed. The specific objectives were as follow: (1) to investigate the influence of rainwater uptake and leaf water potential on water consumption after rainfall events, and (2) to assess the mixed afforestation effect on these influences.

\section{Materials and methods}

\subsection{Study site}

The study was conducted in the Ansai Ecological Station in the semiarid Loess Plateau $\left(36.55^{\circ} \mathrm{N}\right.$, 109.16 ${ }^{\circ}$ ), Northern China. The study area has a semiarid continental climate. The annual average (mean $\pm \mathrm{SD}$ ) rainfall amount and air temperature are $493.1 \pm 127.9 \mathrm{~mm}$ and $10.7 \pm 0.5^{\circ} \mathrm{C}(1985-2017)$, et al., 2019).

Three plantations were chosen for the study: pure $H$. rhamnoides plantation, pure $P$. davidiana 
plantation, and H. rhamnoides-P. davidiana mixed plantation. All plantations were planted in 2004, and three adjacent plots were selected $(16 \mathrm{~m} \times 10 \mathrm{~m})$ for each plantation type. In pure plantations, the original planted spacing for each individual plant was $2.0 \mathrm{~m} \times 2.0 \mathrm{~m}$. In the mixed plantation, $P$. davidiana was originally planted between the $4.0 \mathrm{~m}$ gaps in rows of $H$. rhamnoides, each individual plant was also spaced $2.0 \mathrm{~m} \times 2.0 \mathrm{~m}$. Based on a survey performed in July 2018 , in pure plantations, the average tree trunk diameter (at $1.2 \mathrm{~m}$ height above the ground) and height were $50.5 \pm 3.6 \mathrm{~mm}$ and 4.11 $\pm 0.81 \mathrm{~m}$ for $H$. rhamnoides, respectively, and the corresponding values were $52 \pm 4.6 \mathrm{~mm}$ and $4.05 \pm$ $0.63 \mathrm{~m}$ for $P$. davidiana. Meanwhile, in mixed plantations, the average trunk diameter and tree height were $51.3 \pm 2.9 \mathrm{~mm}$ and $4.49 \pm 0.7 \mathrm{~m}$ for $H$. rhamnoides, respectively, and the corresponding values were $56.3 \pm 3.8 \mathrm{~mm}$ and $4.23 \pm 0.79 \mathrm{~m}$ for P. davidiana. Bothriochloa ischaemum and Glycyrrhiza uralensis were the dominant herbaceous species in $H$. rhamnoides and $P$. davidiana pure plantations, respectively; meanwhile, $B$. ischaemum was dominant in the mixed plantation.

\subsection{Environmental parameter measurements and reference evapotranspiration calculation}

Net radiation ( $\mathrm{R}_{\mathrm{n}}, \mathrm{CNR} 4$, Kipp \&Zone Inc., Netherlands), atmospheric pressure (CS105, Vaisala Inc., Finland), air temperature $\left(\mathrm{T}_{\mathrm{a}}\right)$ and relative humidity (HMP45D, Vaisala Inc.), and wind velocity (Ws, A100R, Vector Inc., UK) were measured using a weather station nearly $500 \mathrm{~m}$ from the research plots. Soil heat flux (G) and rainfall amount were measured at $5 \mathrm{~cm}$ below ground using two HFT-3 plates (Campbell Scientific Inc., USA) and a TE525 rain gauge (Campbell Scientific Inc.), respectively. At each plot, soil water content (SW) was measured at 5, 30, 50, 100, 150, and $200 \mathrm{~cm}$ below ground $\left(\mathrm{SW}_{5 \mathrm{~cm}}, \mathrm{SW}_{30 \mathrm{~cm}}, \mathrm{SW}_{50 \mathrm{~cm}}, \mathrm{SW}_{100 \mathrm{~cm}}, \mathrm{SW}_{150 \mathrm{~cm}}\right.$, and $\left.\mathrm{SW}_{200 \mathrm{~cm}}\right)$ by CS615 TDR probes (Campbell Scientific Inc.). All these parameters were measured and stored at $30 \mathrm{~min}$ interval by a CR3000 datalogger (Campbell Scientific Inc.).

Reference evapotranspiration $\left(\mathrm{ET}_{0}\right)$ was used to indicate atmospheric evaporative demand (Allen et

al., 1998): $E T_{0}=\left(0.408 \times s \times\left(R_{n}-G\right)+\gamma \times \frac{900}{T_{a}+273} \times W_{s} \times V P D\right) /\left(s+\gamma \times\left(1+0.34 \times W_{s}\right)\right)$

where $\gamma$ and $s$ are the psychrometric constant $\left(\mathrm{kPa} \mathrm{K}^{-1}\right)$ and the slope between saturation vapor pressure 
and air temperature $\left(\mathrm{kPa} \mathrm{K}^{-1}\right)$, respectively. The units of $R_{n}$ and $G$ are $\mathrm{W} \mathrm{m}^{-2}$, and of $W_{s}$ is $\mathrm{m} \mathrm{s}^{-1}$.

\subsection{Sap flow observation}

Three standard individuals, with approximately mean height and trunk diameter, for specific species were chosen in each of the nine plots (Table S1). In each plot in the mixed plantation, three individuals of $H$. rhamnoides were chosen firstly, then a neighboring $P$. davidiana individual was selected at approximately $2 \mathrm{~m}$ distance from each chosen $H$. rhamnoides individual. The sap flow was monitored by a pair of Granier-type thermal dissipation probes $10 \mathrm{~mm}$ in length and $2 \mathrm{~mm}$ in diameter in 36 selected individuals. During the plant growing season and ranging from 1 June (DOY 152) to 30 September (DOY 273) in 2018, the 30 s original and 30 min average sap flow values were monitored using a CR3000 data logger (Campbell Scientific Inc.). Waterproof silicone and aluminum foil were used to avoid the impact of the external environment on and physical damage to TDPs (Du et al., 2011). The standard sap flow density $\left(\mathrm{F}_{\mathrm{d}}, \mathrm{ml} \mathrm{m}^{-2} \mathrm{~s}^{-1}\right)$ was calculated as follows (Granier, 1987):

$$
F_{d}=119\left(\left(\Delta t_{\max }-\Delta t\right) / \Delta t\right)^{1.231}
$$

where $\Delta t$ and $\Delta t_{\max }$ are the temperature difference of heated and unheated probes at $30 \mathrm{~min}$ intervals and the maximum $\Delta t$ in each day, respectively.

Steppe et al. (2010) suggested that $F_{d}$ should have a species specific calibration to validate Eq. (2). Meanwhile, the possibility of underestimating the $F_{d}$ value with the Granier-type thermal dissipation method (Du et al., 2011) should be considered when the whole tree water consumption is calculated. However, with the lack of species specific calibration for Eq. (2) in the present study, the daily normalized $F_{d}$ for each replicate individual was calculated as the index of plant water consumption, through dividing $F_{d}$ by the maximum value from DOY 152 to DOY 273. Thus, each monitored individual had a maximum daily normalized $F_{d}$ of 1 . In each plantation type, the average daily normalized $F_{d}$ for plant species was calculated in each plot to determine the water consumption characteristics rather than the absolute water consumption amount (Du et al., 2011). 
From April to October 2018, at the end of each rainfall event, 19 rainwater samples were collected immediately using a rain gauge cylinder placed in the middle of the plantation plots, and stored at $4{ }^{\circ} \mathrm{C}$. To avoid the influence of sample collection on sap flow observation, one standard individual for the specific species nearby each sap flow monitored individual was selected for plant stem and soil water collection. In the mixed plantation, the distance was approximately $2 \mathrm{~m}$ between the selected $H$. rhamnoides and $P$. davidiana standard individuals in each plot for sample collection. For plant stem and soil water collection, five rainfall events were selected: $3.4 \mathrm{~mm}$ (DOY 194), $7.9 \mathrm{~mm}$ (DOY 266), 15.4 mm (DOY 249), $24 \mathrm{~mm}$ (DOY 204), and $35.2 \mathrm{~mm}$ (DOY 156). These rainfall events were selected with an interpulse period longer than 7 days to eliminate the potential influence of the previous rainfall event. At each of successive three days after every selected rainfall event, one suberized stem after removing the bark was collected at midday (11:30-13:30) for each standard individual. Meanwhile, approximately $0.5 \mathrm{~m}$ around the stem of each standard individual in the pure plantations and at the middle between two species in the mixed plantation, one soil core at seven depths (0-10, 10-20, 20-30, 30-50, 50-100, 100-150, and 150-200 cm) was collected through soil drilling. The suberized stem and one part of the collected soil samples were placed into glass bottles. These bottles were sealed with parafilm and stored at $-15{ }^{\circ} \mathrm{C}$.

A vacuum line (LI-2100, LICA Inc., China) was used to extract water from soil samples and plant stems. The water isotopic values of rainwater, soil samples, and plant stems were determined using a DLT-100 water isotope analyzer (LGR Inc., USA), with accuracy of $\pm 0.1\left(\delta^{18} \mathrm{O}\right)$ and $\pm 0.3 \%$ o $(\delta \mathrm{D})$. The potential influence of organic matter on water isotopic values produced during water extraction from stems was eliminated using the method of Yang et al. (2015). The isotopic values (\%) were calculated as follows:

$\delta^{18} \mathrm{O}(\mathrm{D})=\left(R_{\text {sample }}-R_{\text {standard }}\right) / R_{\text {standard }} \times 1000 \%$

where $R_{\text {standard }}$ and $R_{\text {sample }}$ indicate the ${ }^{18} \mathrm{O} /{ }^{16} \mathrm{O}(\mathrm{D} / \mathrm{H})$ molar ratios of water sample relative to the Vienna Standard Mean Ocean Water, respectively. The average water $\delta^{18} \mathrm{O}$ and $\delta \mathrm{D}$ of plant stems for specific species and corresponding soil samples was calculated in each plot for further analysis.

In the present study, the rainwater uptake proportion (RUP, \%) for plant is calculated as the 
proportion of rainwater in plant stem as follows (Cheng et al., 2006):

$\delta^{18} \mathrm{O}(\mathrm{D})_{\mathrm{P}}=P A P \times \delta^{18} \mathrm{O}(\mathrm{D})_{\mathrm{rain}}+(1-P A P) \times \delta^{18} \mathrm{O}(\mathrm{D})_{\mathrm{swb}}$

where $\delta^{18} \mathrm{O}(\mathrm{D})_{\text {rain }}$ and $\delta^{18} \mathrm{O}(\mathrm{D})_{\mathrm{p}}$ are the isotopic values for rainwater and plant stem after rainfall, respectively; $\delta^{18} \mathrm{O}(\mathrm{D})_{\mathrm{swb}}$ and $\delta^{18} \mathrm{O}(\mathrm{D})_{\mathrm{swa}}$ are the isotopic values of soil water immediately before and after rainfall, respectively. Equation (5) is derived through the linear mixing model for water isotopic value in plant stem after rainfall in Eq. (4).

Equations (4) and (5) are based on the assumption that little or no soil water is lost through evaporation. Thus, in this study, only the values of plant stem and soil water collected on the first day immediately after rainfall were used, and only the RUP on the first day after each rainfall event was calculated.

In this study, the $\delta^{18} \mathrm{O}(\mathrm{D})_{\mathrm{swb}}$ cannot be directly accurately determined through soil water sample collection, due to unpredictable natural rainfall events. A linear mixed model can be used to calculate the $\delta^{18} \mathrm{O}(\mathrm{D})_{\mathrm{swb}}$, based on the isotopic values for rainwater and soil water after rainfall, and soil depth interval weighted $\mathrm{SW}$ before $\left(S W_{b}, \mathrm{~m}^{3} \mathrm{~m}^{-3}\right)$ and after $\left(S W_{a}, \mathrm{~m}^{3} \mathrm{~m}^{-3}\right)$ rainfall:

$\delta^{18} \mathrm{O}(\mathrm{D})_{\mathrm{swb}}=S W_{b} / S W_{a} \times \delta^{18} \mathrm{O}(\mathrm{D})_{\mathrm{swa}}+\left(1-S W_{b} / S W_{a}\right) \times \delta^{18} \mathrm{O}(\mathrm{D})_{\mathrm{rain}}$

In addition, on the first day after rainfall, the relative water uptake proportions from different soil depths were calculated using the MixSIR program (Moore and Semmens, 2008). The model input parameters were the average $\delta^{18} \mathrm{O}$ and $\delta \mathrm{D}$ values in plant stem water, soil water at seven depths in each plot, and rainfall water. The SD for $\delta^{18} \mathrm{O}$ and $\delta \mathrm{D}$ at each soil depth was used to accommodate the uncertainties of these values, and no fractionation was considered during water source uptake by plant roots. In addition, the calculated water uptake proportions from seven soil depths were combined into three soil layers (shallow, middle, and deep) to facilitate water source comparisons, for soil depths of 0 30, 30-100, and 100-200 cm, respectively.

In this study, on the first day after rainfall, the water uptake proportions from rainwater and soil 
layers were calculated separately. The sum of RUP and relative water uptake proportions from three soil layers were larger than $100 \%$. Thus, no significant difference was determined between RUP and water sources from different soil layers in the following analysis.

\subsection{Leaf water potential measurement}

On the same day as plant stem and soil sample collections, the $\Psi_{\mathrm{pd}}$ and $\Psi_{\mathrm{m}}$ were measured by a PMS1515D analyzer (PMS Instrument, Corvallis Inc., OR, USA) at 4:30-5:30 (predawn) and 11:2012:40 (midday), respectively. One leaf was selected for each sap flow monitored individual, and the average value for each species in each plot was used for further analysis. The diurnal variation in leaf water potential $\left(\Psi_{\mathrm{pd}}-\Psi_{\mathrm{m}}\right)$ was used to illustrate the leaf water potential gradient.

\subsection{Plant fine root investigation}

In August 2018, six soil cores were dug around each selected standard individual for plant stem and soil water collection, through a soil drill with diameter $20 \mathrm{~cm}$ to investigate plant fine roots. The collected soil depths were $0-10,10-20,20-30,30-50,50-70,70-100,100-130,130-160,160-200 \mathrm{~cm}$, with approximately $0.5 \mathrm{~m}$ around the stem of each species standard individual. WinRHIZO (Regent Instruments Inc., Quebec, Canada) was used to determine the fine root (diameter $<2 \mathrm{~mm}$ ) surface area at each soil depth. The sum of fine root surface area for six soil cores was used to determine the fine root distribution for each selected standard individual.

\subsection{Statistical analysis}

In the present study, the first day after rainfall was the maximum normalized $\mathrm{F}_{\mathrm{d}}$ within 3 days for $H$. rhamnoides and $P$. davidiana in both plantation types, except after 24 and $35.2 \mathrm{~mm}$ for $P$. davidiana in pure plantation. The maximum normalized $\mathrm{F}_{\mathrm{d}}$ for $P$. davidiana in pure plantation was observed on the second day after these two rainfall events. However, for $P$. davidiana in pure plantation, there was no significant difference $(\mathrm{P}>0.05)$ in diurnal sap flow between the first and second day after each of these two rainfall events based on independent-sample $t$-test (Fig S1). Therefore, the normalized $\mathrm{F}_{\mathrm{d}}$ on the 

daily normalized $\mathrm{F}_{\mathrm{d}}\left(\mathrm{SF}_{\mathrm{R}}, \%\right)$ to rainfall pulses:

$$
S F_{R}=\left(\left(X_{\text {after }}-X_{\text {before }}\right) / X_{\text {before }}\right) \times 100 \%
$$

where $X_{\text {after }}$ and $X_{\text {before }}$ are the normalized $\mathrm{F}_{\mathrm{d}}$ on the first day after and on the day before the rainfall event, respectively.

Meanwhile, none of $\Psi_{\mathrm{pd}}, \Psi_{\mathrm{m}}$ nor $\Psi_{\mathrm{pd}}-\Psi_{\mathrm{m}}$ showed significant differences between the first and second day after each rainfall events $(\mathrm{P}>0.05)$ for these two species in both plantation types (Table S2). The $\Psi_{\mathrm{pd}}, \Psi_{\mathrm{m}}$, and $\Psi_{\mathrm{pd}}-\Psi_{\mathrm{m}}$ on the first day after each rainfall event were used in the following analysis to illustrate the influence of leaf water potential on $\mathrm{SF}_{\mathrm{R}}$ in response to rainfall pulses.

A repeated ANOVA (ANOVAR) was used to analyze the differences in water consumption, water sources, and plant physiological parameters between these species in pure and mixed plantations, respectively. This analysis was conducted with $\mathrm{SF}_{\mathrm{R}}$, RUP, relative water uptake proportions from three soil depths, and $\Psi_{\mathrm{pd}}-\Psi_{\mathrm{m}}$ as response variables, and "species" and "rainfall" as between-subject and within-subject factors. The same analysis was used to detect mixed afforestation effect on response variables for each plant species, with "plantation type" and "rainfall" as the between-subject factor. Furthermore, significant differences in fine root proportion for each soil layer (shallow, middle, and deep) for each species between pure and mixed plantations were detected through independent-sample $t$-test. All of these analyses were calculated with SPSS 18 (IBM Inc., New York, US), after data normal distribution and homogeneity of variance analysis were tested.

\section{Results}

\subsection{Variation in environmental parameters and plant fine root vertical distribution}

The rainfall amount during the study period $(265.7 \mathrm{~mm}$, DOY 152-273) was $11.8 \%$ lower than the average value during 2008-2017. Rainfall varied seasonally with 36 consecutive days had no rainfall event (DOY 157-192) and 5 days had successive rainfall events (DOY 237-241) (Fig 1). The ET $_{0}$ $(554.7 \mathrm{~mm})$ was approximately twice the rainfall amount during the study period, with the higher and lower values during the low and high rainfall event periods, respectively (Fig 1). The SW increased and 
subsequently decreased by different degrees following rainfall events, with shallow soil layer $(0-30 \mathrm{~cm})$ exhibited higher variation than the corresponding value below $30 \mathrm{~cm}$ in the three plantations (Fig 1). The coefficients of variation (CVs) in the shallow soil layer were $19.22 \%, 18.56 \%$, and $16.61 \%$ in $H$. rhamnoides and $P$. davidiana pure plantations and the mixed plantation, respectively. The SW for shallow and middle $(30-100 \mathrm{~cm})$ soil layers exhibited lower values than some deep soil layers (100-200 $\mathrm{cm}$ ) during the less rainfall event period (such as DOY 157-192) in the three plantations. In addition, compared with shallow and middle soil layers, the deep soil layer SW exhibited a time lag response to rainfall events. distributions, with more than $40 \%$ of fine roots observed in shallow and deep soil layers, respectively (Fig S2). In the mixed plantation, approximately $40 \%$ of $H$. rhamnoides fine roots were in the shallow soil layer. Meanwhile, no significant differences in fine root proportion were observed for $H$. rhamnoides for each soil layer in pure and mixed plantations $(\mathrm{P}>0.05)$. The proportion of $P$. davidiana in the mixed plantation $(d f=4, t=7.15, \mathrm{P}<0.01)$.
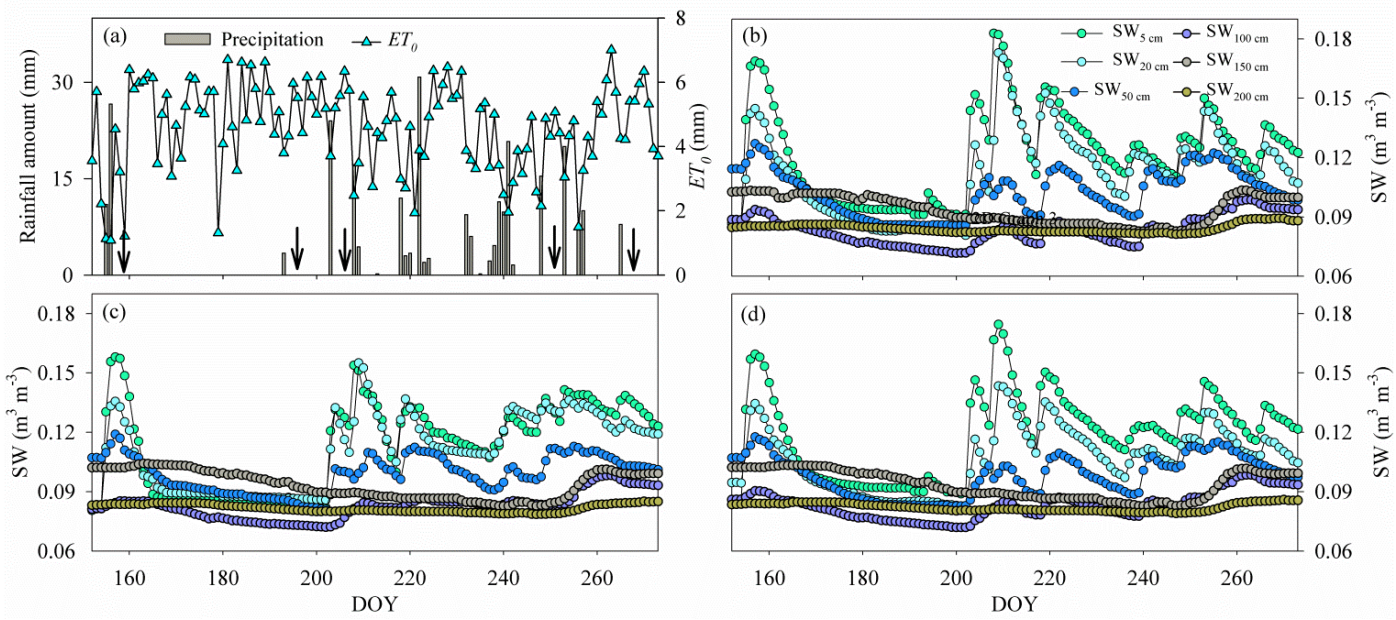

Figure 1. Variation of (a) rainfall amount, reference evapotranspiration $\left(\mathrm{ET}_{0}\right)$, and averaged soil water content (SW) in (b) H. rhamnoides pure plantation, (c) P. davidiana pure plantation, and (d) mixed plantation from DOY 152 to 273 (1 June to 30 September). Standard deviation bars for SW at each soil layers are not shown to allow clear display of variation of SW for each plot. Arrows in (a) indicate dates 
of sample collection: DOY 157-159 (6-8 June), DOY 194-196 (12 -14 July), DOY 204-206 (23-25 July), DOY 249-251 (6-8 September), and DOY 265-267 (22-24 September).

\subsection{Variations in sap flow}

Daily normalized $\mathrm{F}_{\mathrm{d}}$ for $H$. rhamnoides and $P$. davidiana fluctuated with rainfall events in pure and mixed plantations (Fig 2). The variation of normalized $\mathrm{F}_{\mathrm{d}}$ for $H$. rhamnoides and $P$. davidiana in mixed plantation was higher than the specific species in pure plantations, with corresponding CVs of $30.99 \%$ and $34.88 \%$ in the mixed plantation, and $24.64 \%$ and $27.44 \%$ in pure plantations (Fig 2). The relative response of water consumption to rainfall pulses was significantly influenced by both rainfall amount and plant species $(\mathrm{P}<0.001)$ (Fig 2, Table 1). Following large rainfall amounts $(\geq 15.4 \mathrm{~mm})$, the diurnal variation of sap flow was significantly higher than the value before rainfall $(\mathrm{P}<0.05)$ for $H$. rhamnoides in pure plantation and for P. davidiana in both plantation types (Figs S3 and S4). The lowest rainfall amount $(7.9 \mathrm{~mm})$ that significantly increased the diurnal variation of sap flow was observed for $H$. rhamnoides in the mixed plantation (Fig S3). Furthermore, in response to rainfall pulses, the $\mathrm{SF}_{\mathrm{R}}$ for $H$. rhamnoides in pure (range $6.69 \pm 1.22 \%$ to $106.34 \pm 4.7 \%$ ) and mixed (range $2.23 \pm 0.54 \%$ to $190.89 \pm$ $15.49 \%)$ plantations was significantly higher $(\mathrm{P}<0.001)$ than corresponding values for $P$. davidiana: ranges $4.24 \pm 0.52 \%$ to $60.28 \pm 5.72 \%$ and $3.14 \pm 0.53 \%$ to $83.04 \pm 14.23 \%$ (Table 1 ). Mixed afforestation significantly enhanced $\mathrm{SF}_{\mathrm{R}}$ for both species $(\mathrm{P}<0.001)$ (Table 1).

Table 1. Repeated ANOVA (ANOVAR) parameters for the relative response of normalized sap flow $\left(\mathrm{SF}_{\mathrm{R}}\right)$ to rainfall pulses of $H$. rhamnoides and $P$. davidiana $(\mathrm{n}=30)$.

\begin{tabular}{ccccc}
\hline & Variation source & $d f$ & $F$ & $p$ \\
\hline Rainfall & 4 & 97.91 & $<0.001$ \\
Pure plantation & Species & 1 & 121.13 & $<0.001$ \\
& & 4 & 27.35 & $<0.001$ \\
Rainfall $\times$ Species & & & \\
Mixed plantation & Rainfall & 4 & 489.9 & $<0.001$ \\
& Species & 1 & 70.38 & $<0.001$ \\
\hline
\end{tabular}




\begin{tabular}{|c|c|c|c|c|}
\hline & Rainfall $\times$ Species & 4 & 249.17 & $<0.001$ \\
\hline & Rainfall & 4 & 42.63 & $<0.001$ \\
\hline \multirow[t]{3}{*}{ H. rhamnoides } & Plantation type & 1 & 337.09 & $<0.001$ \\
\hline & Rainfall $\times$ Plantation type & 4 & 215.43 & $<0.001$ \\
\hline & Rainfall & 4 & 10.05 & $<0.001$ \\
\hline \multirow[t]{2}{*}{ P. davidiana } & Plantation type & 1 & 32.36 & $<0.01$ \\
\hline & Rainfall $\times$ Plantation type & 4 & 19.12 & $<0.001$ \\
\hline
\end{tabular}

$d f=$ degree of freedom, Plantation type $=$ pure and mixed plantation for each species. Pure and Mixed plantation indicate the result of $\mathrm{SF}_{\mathrm{R}}$ for both species in different plantation types, respectively; H. rhamnoides and P. davidiana
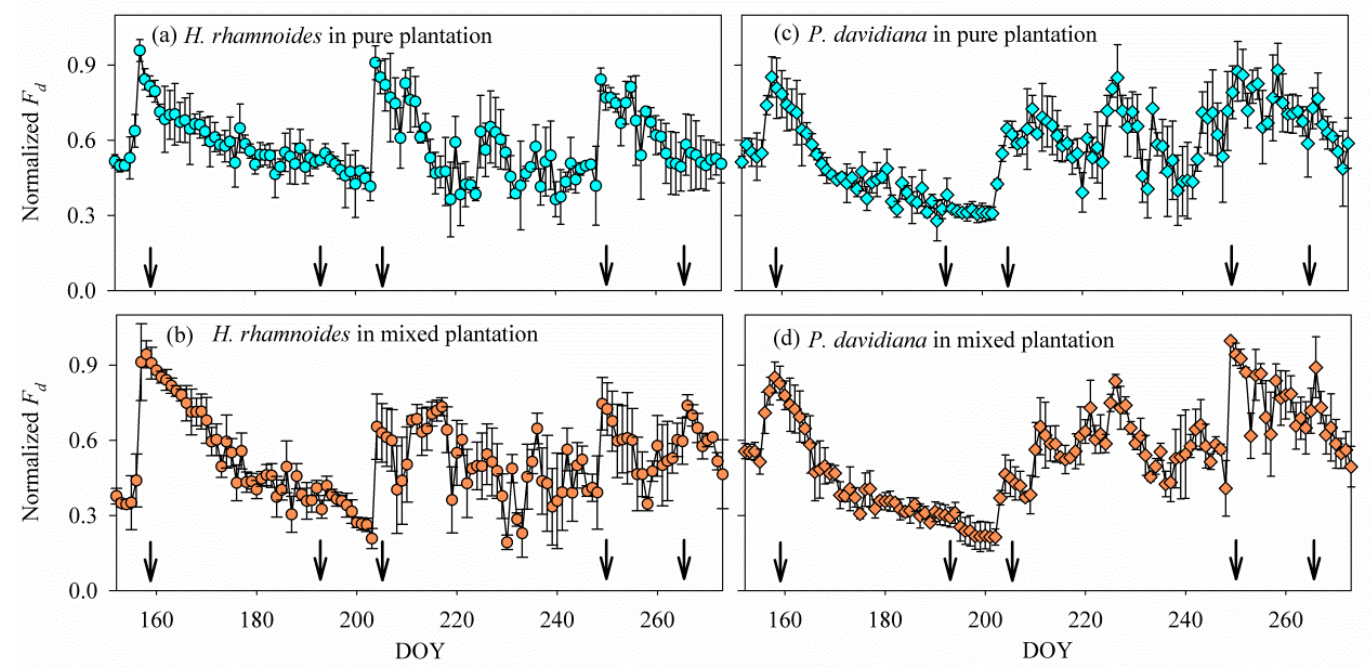

Figure 2. Variation in averaged $\left( \pm \mathrm{SD}\right.$ ) daily normalized $\mathrm{F}_{\mathrm{d}}$ for $H$. rhamnoides in (a) pure and (b) mixed plantations and for P. davidiana in (c) pure and (d) mixed plantations. Arrows indicate dates of sample collection: DOY 157-159 (6-8 June), DOY 194-196 (12 -14 July), DOY 204-206 (23-25 July), DOY 249-251 (6-8 September), and DOY 265-267 (22 -24 September).

\subsection{Variations in plant water sources}

The soil water $\delta^{18} \mathrm{O}$ and $\delta \mathrm{D}$ for pure $H$. rhamnoides, pure $P$. davidiana, and mixed plantations showed 
vertical variations following large rainfall events $(\geq 15.4 \mathrm{~mm}$ ) (Fig S5). Generally, the isotopic values of soil water depleted from shallow to deep soil layers, and water isotopic values in shallow and middle soil layer were close to rainfall water in the three plantations following large rainfall events.

Although no significant difference in RUP was observed between $H$. rhamnoides $(14.2 \pm 7.81 \%)$ and P. davidiana $(12.43 \pm 7.33 \%$ ) in pure plantations (Fig 3, Table 2), the RUP was significantly higher for H. rhamnoides $(19.17 \pm 8.6 \%)$ than $P$. davidiana $(14.59 \pm 5.86 \%)$ in the mixed plantation $(\mathrm{P}<0.05)$ (Table 2). In addition, $H$. rhamnoides mainly uptake water from the middle soil layer in pure and mixed plantations based on the MixSIR result, with corresponding average values of $36.27 \pm 2.43 \%$ and 44.14 $\pm 3.06 \%$ (Fig 4). The water source for $P$. davidiana in pure and mixed plantations was mainly from the deep and middle soil layers, respectively, with corresponding average values of $41.4 \pm 15.18 \%$ and $40.17 \pm 5.9 \%$. In pure plantation, the water source from shallow and middle soil layers for $H$. rhamnoides was significantly higher than $P$. davidiana; however, the water source from the deep soil layer was significantly lower for the former species $(\mathrm{P}<0.05)$ (Table 3). No significant differences in water sources from each soil layer were observed between these species in the mixed plantation (Table 3). In addition, mixed afforestation significantly enhanced RUP and decreased the deep soil water uptake proportion for H. rhamnoides and P. davidiana $(\mathrm{P}<0.05)$ (Tables 2 and 3, Figs 3 and 4).
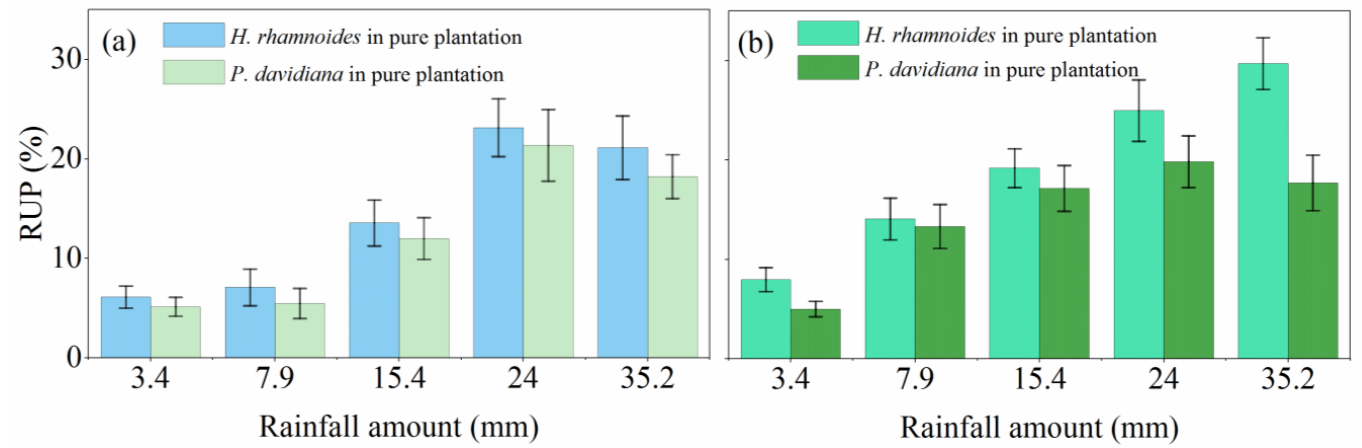

Figure 3. Variation in averaged $( \pm \mathrm{SD}$ ) rainwater uptake proportion (RUP) for $H$. rhamnoides and $P$. davidiana in (a) pure and (b) mixed plantations after five rainfall events. 


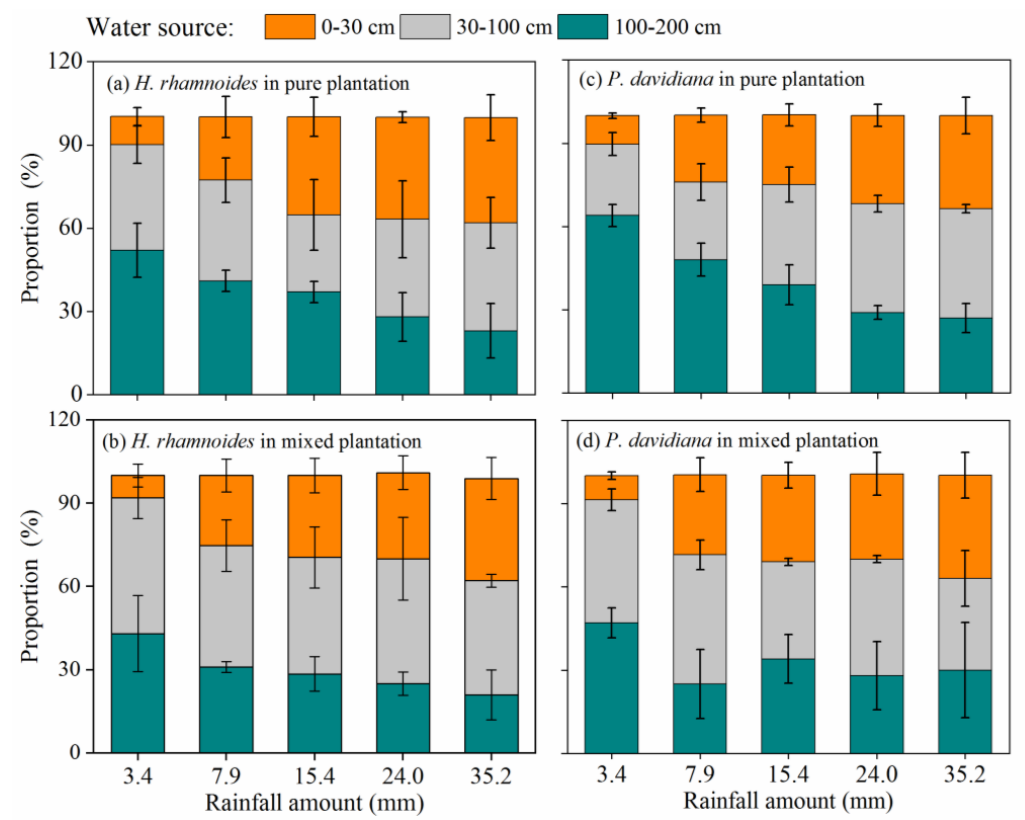

Figure 4. Variation in averaged $( \pm$ SD) plant water sources from three soil layers $(0-30,30-100$, and 100-200 cm) for H. rhamnoides in (a) pure and (b) mixed plantations, and for P. davidiana in (c) pure and (d) mixed plantations after five rainfall events.

Table 2. Repeated ANOVA (ANOVAR) parameters for rainwater uptake proportion (RUP) for $H$. rhamnoides and P. davidiana $(\mathrm{n}=30)$.

\begin{tabular}{|c|c|c|c|c|}
\hline & Variation source & $d f$ & $F$ & $p$ \\
\hline \multirow{3}{*}{ Pure Plantation } & Rainfall & 4 & 385.02 & $<0.01$ \\
\hline & Species & 1 & 21.02 & $<0.05$ \\
\hline & Rainfall $\times$ Species & 4 & 0.83 & 0.52 \\
\hline \multirow{3}{*}{ Mixed Plantation } & Rainfall & 4 & 17696.38 & $<0.01$ \\
\hline & Species & 1 & 4089.12 & $<0.01$ \\
\hline & Rainfall $\times$ Species & 4 & 1776.62 & $<0.01$ \\
\hline \multirow{3}{*}{ H. rhamnoides } & Rainfall & 4 & 496.72 & $<0.01$ \\
\hline & Plantation type & 1 & 360.16 & $<0.01$ \\
\hline & Rainfall $\times$ Plantation type & 4 & 17.62 & $<0.01$ \\
\hline
\end{tabular}




\begin{tabular}{|c|c|c|c|c|}
\hline \multirow{3}{*}{ P. davidiana } & Rainfall & 4 & 1969.3 & $<0.01$ \\
\hline & Plantation type & 1 & 54.83 & $<0.01$ \\
\hline & Rainfall $\times$ Plantation type & 4 & 208.06 & $<0.01$ \\
\hline
\end{tabular}

$d f=$ degree of freedom, Plantation type = pure and mixed plantation for each species. Pure and Mixed plantation indicate the result of $\mathrm{SF}_{\mathrm{R}}$ for both species in different plantation types, respectively; H. rhamnoides and P. davidiana indicate the mixed afforestation effect on $\mathrm{SF}_{\mathrm{R}}$ for these species.

Table 3. Repeated ANOVA (ANOVAR) parameters for relative water uptake proportion from shallow (0-30 cm), middle (30-100 cm), and deep (100-200 cm) soil layer for $H$. rhamnoides and P. davidiana $(\mathrm{n}=30)$.

\begin{tabular}{|c|c|c|c|c|c|c|c|c|}
\hline & \multirow{2}{*}{ Variation source } & \multirow{2}{*}{$d f$} & \multicolumn{2}{|c|}{$0-30 \mathrm{~cm}$} & \multicolumn{2}{|c|}{$30-100 \mathrm{~cm}$} & \multicolumn{2}{|c|}{$100-200 \mathrm{~cm}$} \\
\hline & & & $F$ & $p$ & $F$ & $p$ & $F$ & $p$ \\
\hline & Rainfall & 4 & 153.45 & $<0.01$ & 145.04 & $<0.01$ & 176.79 & $<0.01$ \\
\hline \multirow[t]{2}{*}{ Pure Plantation } & Species & 1 & 8.69 & $<0.05$ & 10.56 & $<0.05$ & 11.08 & $<0.05$ \\
\hline & Rainfall $\times$ Species & 4 & 129.89 & $<0.01$ & 112.46 & $<0.01$ & 4.99 & $<0.01$ \\
\hline \multirow{3}{*}{$\begin{array}{c}\text { Mixed } \\
\text { Plantation }\end{array}$} & Rainfall & 4 & 1.5 & 0.41 & 2.3 & 0.11 & 18.34 & $<0.01$ \\
\hline & Species & 1 & 2.2 & 0.21 & 1.48 & 0.29 & 3.9 & 0.12 \\
\hline & Rainfall $\times$ Species & 4 & 0.9 & 0.48 & 2.41 & 0.09 & 1.9 & 0.16 \\
\hline \multirow{3}{*}{ H. rhamnoides } & Rainfall & 4 & 2.05 & 0.14 & 1.51 & 0.25 & 85.46 & $<0.01$ \\
\hline & Plantation type & 1 & 1.07 & 0.36 & 1.32 & 0.32 & 10.08 & $<0.05$ \\
\hline & Rainfall $\times$ Plantation type & 4 & 0.62 & 0.66 & 1.39 & 0.28 & 5.59 & $<0.01$ \\
\hline \multirow{3}{*}{ P. davidiana } & Rainfall & 4 & 14.72 & $<0.01$ & 71.59 & $<0.01$ & 19.46 & $<0.01$ \\
\hline & Plantation type & 1 & 4.1 & 0.12 & 5.68 & 0.08 & 123.27 & $<0.01$ \\
\hline & Rainfall $\times$ Plantation type & 4 & 9.55 & $<0.01$ & 85.29 & $<0.01$ & 9.35 & $<0.01$ \\
\hline
\end{tabular}
indicate the result of $\mathrm{SF}_{\mathrm{R}}$ for both species in different plantation types, respectively; H. rhamnoides and P. davidiana indicate the mixed afforestation effect on water sources from different soil layers for these species.

\subsection{Variations in plant leaf water potential}

In response to rainfall pulses, $H$. rhamnoides exhibited higher $\mathrm{CV}$ for $\Psi_{\mathrm{pd}}, \Psi_{\mathrm{m}}$, and $\Psi_{\mathrm{pd}}-\Psi_{\mathrm{m}}$ than 
corresponding value for $P$. davidiana in both plantation types, except that $H$. rhamnoides exhibited lower CVs for $\Psi_{\mathrm{pd}}$ than P. davidiana (12.99\% and $18.33 \%$, respectively) in the mixed plantation (Fig 5). Compared with $P$. davidiana, $H$. rhamnoides exhibited significantly positive $\Psi_{\mathrm{pd}}$ in pure plantation, negative $\Psi_{\mathrm{m}}$ in the mixed plantation, and larger $\Psi_{\mathrm{pd}}-\Psi_{\mathrm{m}}$ in both plantation types $(\mathrm{P}<0.05)$ (Table 4). Meanwhile, mixed afforestation significantly reduced the $\Psi_{\mathrm{m}}$ and increased the $\Psi_{\mathrm{pd}}$ for $H$. rhamnoides and $P$. davidiana $(\mathrm{P}<0.05)$, respectively, and significantly increased $\Psi_{\mathrm{pd}}-\Psi_{\mathrm{m}}$ for both species (Table 4).
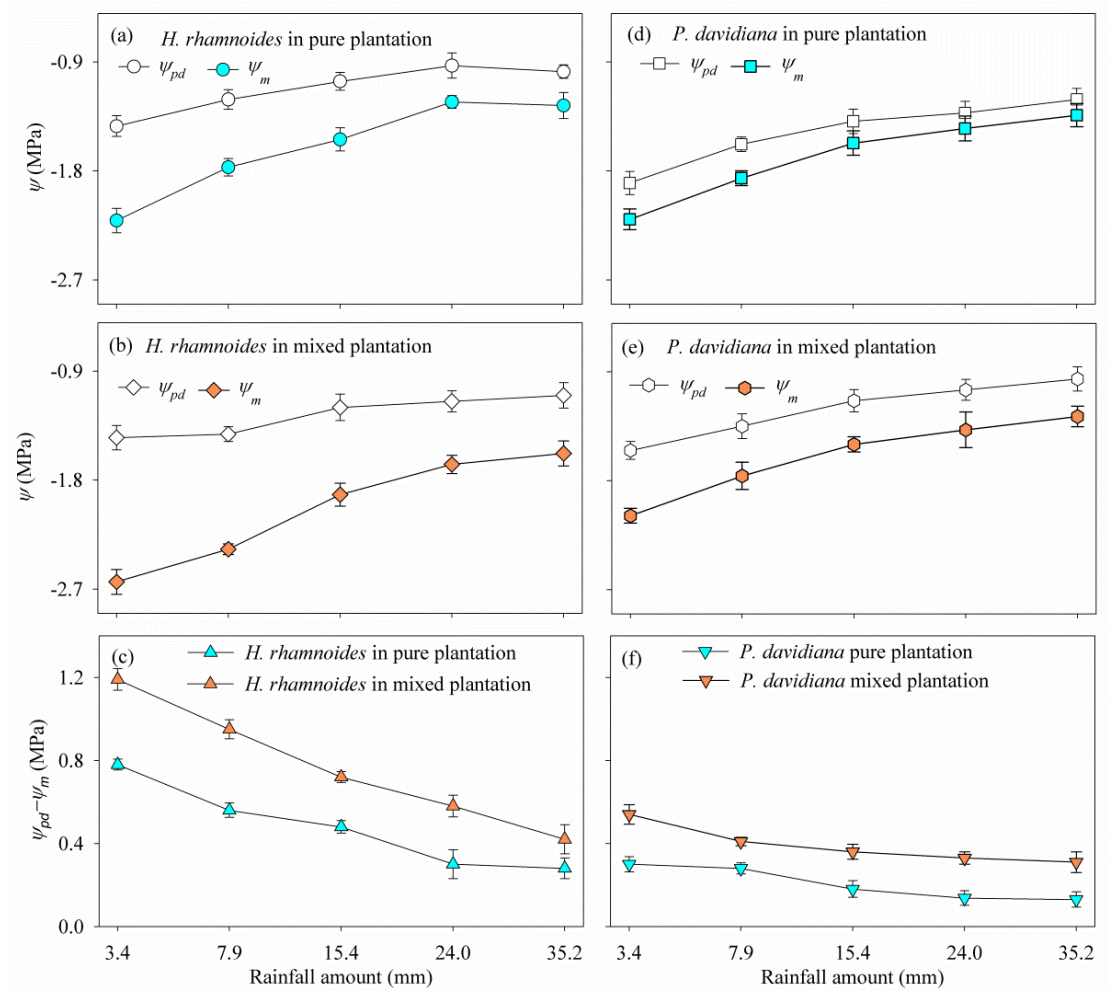

Figure 5. Variation in averaged $( \pm \mathrm{SD})$ plant predawn $\left(\Psi_{\mathrm{pd}}\right)$, midday leaf water potential $\left(\Psi_{\mathrm{m}}\right)$, and leaf water potential gradient $\left(\Psi_{\mathrm{pd}}-\Psi_{\mathrm{m}}\right)$ for $(\mathrm{a}-\mathrm{c}) H$. rhamnoides and $(\mathrm{d}-\mathrm{f}) P$. davidiana in both plantation types after five rainfall events.

Table 4. Repeated ANOVA (ANOVAR) parameters for predawn $\left(\Psi_{\mathrm{pd}}\right)$, midday leaf water potential $\left(\Psi_{\mathrm{m}}\right)$, and leaf water potential gradient $\left(\Psi_{\mathrm{pd}}-\Psi_{\mathrm{m}}\right)$ for $H$. rhamnoides and $P$. davidiana $(\mathrm{n}=30)$.

\begin{tabular}{lccccccccc}
\hline & \multirow{2}{*}{ Variation source } & & \multirow{2}{*}{} & \multicolumn{2}{c}{$\Psi_{p d}$} & & $\Psi_{m}$ & & $\Psi_{p d}-\Psi_{m}$ \\
\cline { 4 - 9 } & & & $F$ & $p$ & $F$ & $p$ & $F$ & $p$ \\
\hline Pure Plantation & Rainfall & 4 & 4.02 & $<0.05$ & 24.44 & $<0.01$ & 47.88 & $<0.01$ \\
\hline
\end{tabular}




\begin{tabular}{|c|c|c|c|c|c|c|c|c|}
\hline & Species & 1 & 182.74 & $<0.01$ & 4.9 & $<0.05$ & 969.97 & $<0.01$ \\
\hline & Rainfall $\times$ Species & 4 & 3.24 & $<0.05$ & 2.08 & 0.13 & 18.68 & $<0.01$ \\
\hline \multirow{3}{*}{ Mixed Plantation } & Rainfall & 4 & 0.66 & 0.63 & 25.54 & $<0.01$ & 82.49 & $<0.01$ \\
\hline & Species & 1 & 0.12 & 0.75 & 127.3 & $<0.01$ & 3420.1 & $<0.01$ \\
\hline & Rainfall $\times$ Species & 4 & 1.8 & 0.18 & 3.7 & $<0.05$ & 35.92 & $<0.01$ \\
\hline \multirow{3}{*}{ H. rhamnoides } & Rainfall & 4 & 7.14 & $<0.01$ & 19.64 & $<0.01$ & 3.59 & $<0.05$ \\
\hline & Plantation type & 1 & 27.05 & $<0.01$ & 496.66 & $<0.01$ & 1278.96 & $<0.01$ \\
\hline & Rainfall $\times$ Plantation type & 4 & 1.69 & 0.202 & 3.32 & $<0.05$ & 6.66 & $<0.01$ \\
\hline \multirow{3}{*}{ P. davidiana } & Rainfall & 4 & 30.78 & $<0.01$ & 12.39 & $<0.01$ & 7.38 & $<0.01$ \\
\hline & Plantation type & 1 & 792.77 & $<0.01$ & 2.97 & 0.16 & 634.12 & $<0.01$ \\
\hline & Rainfall $\times$ Plantation type & 4 & 3.8 & $<0.05$ & 0.09 & 0.98 & 3.83 & $<0.05$ \\
\hline
\end{tabular}

$d f=$ degree of freedom, Plantation type = pure and mixed plantation for each species. Pure and Mixed plantation indicate the result of $\mathrm{SF}_{\mathrm{R}}$ for both species in different plantation types, respectively; H. rhamnoides and P. davidiana indicate the mixed afforestation effect on leaf water potential for these species.

\subsection{Influence of water sources and $\Psi_{\mathrm{pd}}-\Psi_{\mathrm{m}}$ on plant water consumption}

The $\mathrm{SF}_{\mathrm{R}}$ significantly increased with increasing RUP and decreasing $\Psi_{\mathrm{pd}}-\Psi_{\mathrm{m}}$ for $H$. rhamnoides $(\mathrm{P}<$ 0.01) in both plantation types (Fig 6). Meanwhile, $\mathrm{SF}_{\mathrm{R}}$ significantly increased with decreasing $\Psi_{\mathrm{pd}}-\Psi_{\mathrm{m}}$ for $P$. davidiana in both plantation types $(\mathrm{P}<0.05)$. However, a significant relationship between $\mathrm{SF}_{\mathrm{R}}$ and RUP was observed for $P$. davidiana in the mixed $(\mathrm{P}<0.05)$ but not in pure plantations (Fig 6). Furthermore, $\mathrm{SF}_{\mathrm{R}}$ significantly increased with decreasing water uptake proportion from the deep soil layer for H. rhamnoides in both plantation types and P. davidiana in mixed plantation $(\mathrm{P}<0.05)$ (Table S3). No significant relationship was observed between $\mathrm{SF}_{\mathrm{R}}$ and water uptake proportion from shallow or middle soil layers for both species in both plantation types. 

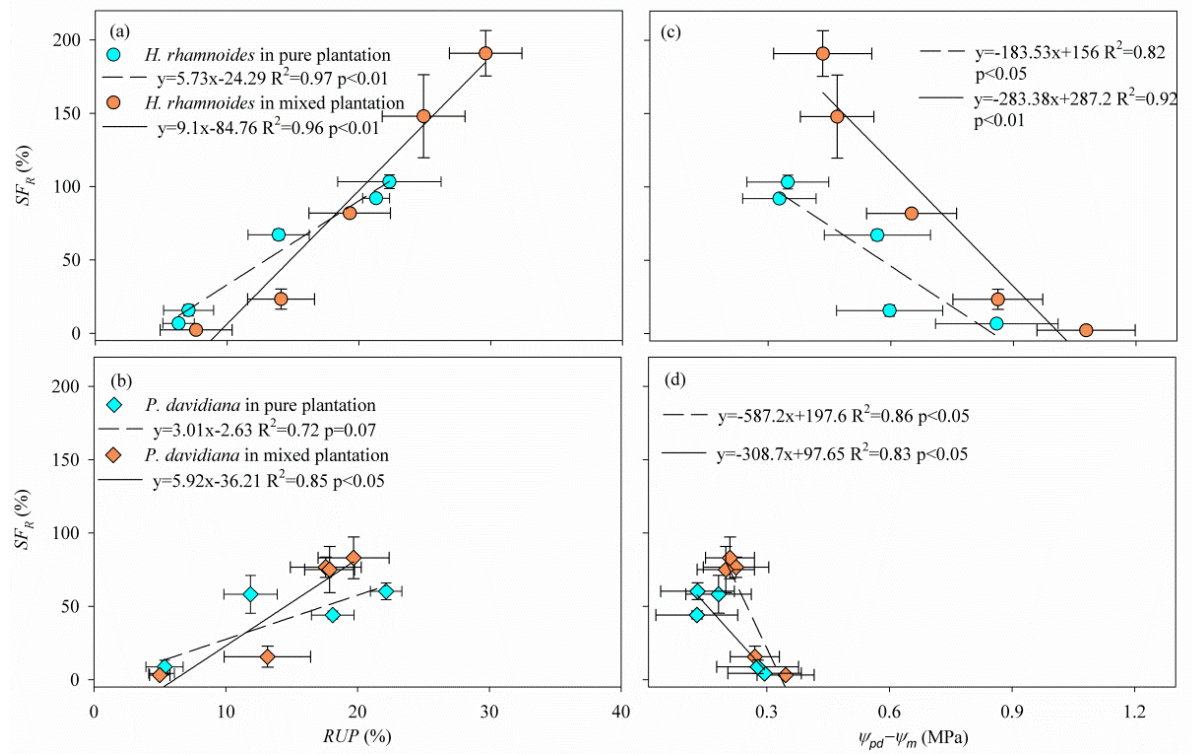

Figure 6. Relationship of (a, b) rainwater uptake proportion (RUP) and (c, d) leaf water potential gradient $\left(\Psi_{\mathrm{pd}}-\Psi_{\mathrm{m}}\right)$ with relative response of normalized $\mathrm{F}_{\mathrm{d}}\left(\mathrm{SF}_{\mathrm{R}}\right)$ for $H$. rhamnoides and P. davidiana in both plantation types.

\section{Discussion}

4.1 Rainwater uptake enhances water consumption for $H$. rhamnoides but not $P$. davidiana in pure plantations

Rainwater is the only replenished soil water source in the studied region, because plants cannot uptake ground water of approximately $100 \mathrm{~m}$ depth below the surface (Wu et al., 2021). Small rainfall events generally only wet the soil surface and may evaporate before plant root uptake (Zhao and Liu, 2010). However, large rainfall events are most likely recharge soil moisture and enhance the metabolic activity of plant fine roots (Hudson et al., 2018), thus enhancing plant water uptake. Similar to Salix psammophila and Caragana korshinskii in the studied region (Zhao et al., 2021), both H. rhamnoides and $P$. davidiana exhibited plasticity in water sources in pure plantations (Fig 4), with $H$. rhamnoides exhibiting the greater plasticity. In pure plantations, the obviously lower SWC at all soil depths (Fig 1) and large water uptake proportion from the deep soil layer (Fig 4) after $3.4 \mathrm{~mm}$ of rainfall for these two species, suggested that this rainfall amount did not relieve the drought caused by 36 days (DOY 157- 

an increase in rainfall amount $(\mathrm{P}<0.05)$ (Fig S6), indicating that water uptake was more sensitive to rainfall for $H$. rhamnoides. This may be mainly due to the greater proportions of fine root surface area distributed in the shallow soil layer for $H$. rhamnoides $(40.85 \pm 3.14 \%)$ compared to $P$. davidiana $(21.94 \pm 2.3 \%)($ Fig S2).

Rainwater uptake does not permit water consumption increase after rainfall pulses especially in semiarid and arid environments (Dai et al., 2020; Grossiord et al., 2017; West et al., 2007), and the influence of water potential gradient $\left(\Psi_{\mathrm{pd}}-\Psi_{\mathrm{m}}\right)$ on plant water consumption should also be considered (Hudson et al., 2018; Kumagai and Porporato, 2012). For example, although Juniperus osteosperma, a deep rooted plant species, could uptake rainwater after large events in the west of the United States, the sap flux did not increase with increasing rainfall amount (West et al., 2007). The synchronization between rainwater uptake and water consumption for $J$. osteosperma was mainly attributed to the uptake of rainwater by plant being unable to reverse the cavitation in its roots and stems (Grossiord et al., 2017; West et al., 2007). Our previous investigations in the studied region indicated that $P$. davidiana is relatively more vulnerable to cavitation than $H$. rhamnoides, with water potential at $50 \%$ loss of conductivity of $-1.15 \mathrm{MPa}$ (Zhang et al., 2013) and -1.49 MPa (Dang et al., 2017), respectively, based on stem vulnerability curves. Being less vulnerable to stem cavitation allowed H. rhamnoides to experience a significantly lower $\Psi_{\mathrm{m}}$ and larger $\Psi_{\mathrm{pd}}-\Psi_{\mathrm{m}}$ compared with $P$. davidiana in response to soil water conditions after rainfall pulses. The large $\Psi_{\mathrm{pd}}-\Psi_{\mathrm{m}}$ for $H$. rhamnoides was consistent with the high $\mathrm{SF}_{\mathrm{R}}$ and $\mathrm{CV}$ s of normalized sap flow, indicating that this species exhibited a rainfall sensitive mechanism. The relative constant $\Psi_{\mathrm{pd}}-\Psi_{\mathrm{m}}$ for $P$. davidiana was consistent with the relatively small $\mathrm{SF}_{\mathrm{R}}$ and CVs of normalized sap flow, indicating that this species exhibited a rainfall insensitive mechanism. Furthermore, after rainfall events, the $\mathrm{SF}_{\mathrm{R}}$ for $H$. rhamnoides but not for $P$. davidiana significantly increased following rainfall amount increases $(\mathrm{P}<0.05)$ (Fig S6), also indicating that water consumption was more sensitive to rainfall for $H$. rhamnoides.

The $\mathrm{SF}_{\mathrm{R}}$ was significantly influenced by RUP and $\Psi_{\mathrm{pd}}-\Psi_{\mathrm{m}}$ for $H$. rhamnoides in the pure plantation, indicating that rainwater uptake and leaf physiological adjustment enhanced its plant water use (Figs 6 
and 7). However, the $\mathrm{SF}_{\mathrm{R}}$ was only significantly influenced by $\Psi_{\mathrm{pd}}-\Psi_{\mathrm{m}}$ for P. davidiana (Fig 7), suggesting that its water use was mainly constrained by plant physiological characteristics. The $\mathrm{ET}_{0}$ represents the atmospheric evaporative demand, and has been observed to influence plant water consumption in water limited (Li et al., 2021) and non-water limited regions (Iida et al., 2016). However, in the present study, neither $\mathrm{ET}_{0}$ after rainfall nor relative response of $\mathrm{ET}_{0}$ significantly influenced $\mathrm{SF}_{\mathrm{R}}$ for either species in pure plantations (Table $\mathrm{S} 4$ ). The influence of plant physiological characteristics (i.e. $\Psi_{\mathrm{pd}}-\Psi_{\mathrm{m}}$ ) on $\mathrm{SF}_{\mathrm{R}}$ for both species, may partially contribute to the lack of atmosphere evaporative demand effect on plant water consumption in the studied region, although these species exhibited different rainfall pulse sensitivity.

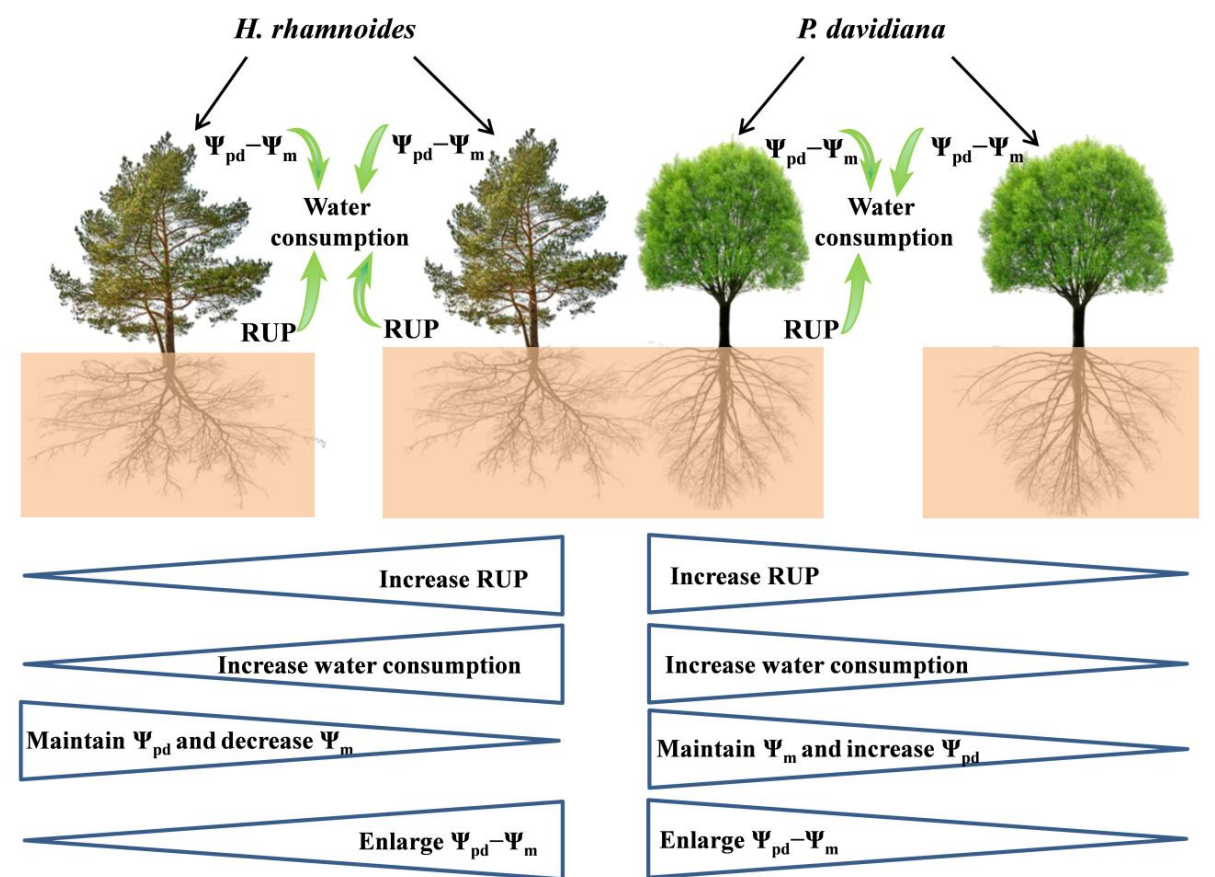

Figure 7. Schematic of rainwater uptake, leaf water potential gradient, and plant water consumption for H. rhamnoides and P. davidiana in both plantation types. Both rainwater uptake proportion (RUP) and leaf water potential gradient $\left(\Psi_{\mathrm{pd}}-\Psi_{\mathrm{m}}\right)$ enhanced plant water consumption after rainfall pulses for $H$. rhamnoides in pure and mixed plantations, and for $P$. davidiana in mixed plantation. However, $\Psi_{\mathrm{pd}}-\Psi_{\mathrm{m}}$ rather than RUP significantly influenced plant water consumption after rainfall pulses for $P$. davidiana in the pure plantation. Mixed afforestation effect of these parameters for each species are indicated at 
the bottom half of the schematic, with "increase", "decrease" or "enlarge" indicating a significant difference $(\mathrm{P}<0.05)$ for a species between pure and mixed plantations. Mixed afforestation significantly enhanced RUP and plant water consumption, decreased $\Psi_{\mathrm{m}}$, and enlarged $\Psi_{\mathrm{pd}}-\Psi_{\mathrm{m}}$ for $H$. rhamnoides, and also significantly enhanced the RUP and water consumption, increased $\Psi_{\mathrm{pd}}$, and enlarged $\Psi_{\mathrm{pd}}-\Psi_{\mathrm{m}}$ for P. davidiana.

\subsection{Rainwater uptake enhances water consumption for coexisting species in mixed plantation}

Spatial water resource partitioning is considered one of the essential plant strategies to maintain coexistence in mixed plantations, especially in semiarid and arid regions (Munoz-Villers et al., 2020; Silvertown et al., 2015; Yang et al., 2020). However, water source competition has widely been observed among coexisting plant species according to the literature surveys by Silvertown et al. (2015) and Tang et al. (2018), regardless of annual average rainfall amount. In the present study, the non-significant differences in xylem $\delta^{18} \mathrm{O}$ and $\delta \mathrm{D}(\mathrm{P}>0.05)$ and plant water sources for the three soil layers (Table 3, Fig 4) indicated water competition between these species in the mixed plantation, although the RUP was significantly higher for $H$. rhamnoides (Table 2).

Generally, two types of adaptation can be adopted by plants to cope with resource competition: increased competition ability or minimized competition interactions (West et al., 2007). Consistent with the first adaptation type, mixed afforestation enhanced the RUP for $H$. rhamnoides and $P$. davidiana (Figs 3 and 7, Table 2). Although mixed afforestation did not significantly alter the $\Psi_{\mathrm{pd}}$ and $\Psi_{\mathrm{m}}$ for $H$. rhamnoides and $P$. davidiana, respectively, significantly negative $\Psi_{\mathrm{m}}$ and positive $\Psi_{\mathrm{pd}}$ were observed for corresponding species $(\mathrm{P}<0.01)$ (Table 4). Mixed afforestation significant increased $\Psi_{\mathrm{pd}}$ for $P$. davidiana, possibly due to the advantage of access to soil moisture recharged by rainwater through an increased root surface area in the shallow soil layer for this species in the mixed plantation (Fig S2). Thus, plant physiological $\left(\Psi_{\mathrm{m}}\right)$ and root morphological adjustments were adopted by $H$. rhamnoides and $P$. davidiana in the mixed plantation, respectively, to significantly enlarge $\Psi_{\mathrm{pd}}-\Psi_{\mathrm{m}}$ and increase RUP (Fig 7). Similar to the result in pure plantations, no significant relationship between $\mathrm{SF}_{\mathrm{R}}$ and $\mathrm{ET}_{0}$ after rainfall and relative response of $\mathrm{ET}_{0}$ was observed for these species in the mixed plantation (Table S4). 

consumption for these species in the mixed plantation in response to rainfall pulses.

Furthermore, consistent with the second adaptation type, mixed afforestation significantly decreased the water uptake proportion from the deep soil layer for these species (Table 3). The increasing rainfall amount significantly decreased water source proportion from deep soil layer $(\mathrm{P}<0.05)$ for $H$. rhamnoides and $P$. davidiana in the mixed plantation (Table S3), with the corresponding values decreasing from $43.13 \pm 13.74 \%$ and $47.07 \pm 5.39 \%$ (both after $3.4 \mathrm{~mm}$ ), respectively, to $21.54 \pm 8.9 \%$ (after $35.2 \mathrm{~mm}$ ) and $28.66 \pm 12.26 \%$ (after $24 \mathrm{~mm}$ ) (Fig 4). Thus, both increased rainwater uptake and decreased water source competition from the deep soil layer were adopted by these species in the mixed plantation to minimize water sources competition under water limited conditions.

\subsection{Implications for plantation species and type selection based on rainwater uptake and consumption}

Rainwater uptake by plant and water consumption response to rainfall pulses may influence plant physiological process and the water cycle (Meier et al., 2018; Zhao et al., 2021). In pure plantations, $H$. rhamnoides rather than $P$. davidiana showed rainwater uptake advantage due to the large $\Psi_{\mathrm{pd}}-\Psi_{\mathrm{m}}$ for the former species, although both species exhibited plasticity in water sources. The excessive water uptake from the deep soil may desiccate deep soil (Wu et al., 2021), weakening plant resilience to drought stress and thus plant community sustainability in this Loess Plateau region (Song et al., 2018; Zhao et al., 2021). Whether rainwater uptake can reduce plant water uptake from deep soil layers is essential for plantation adaptation (West et al., 2012; Wu et al., 2021). In the present study, the proportion of water sources from deep soil layers was significantly decreased with increased rainfall amount for these species in both pure and mixed plantations $(\mathrm{P}<0.05)$, except for $P$. davidiana in pure plantation. Physiological (e.g., $\left.\Psi_{\mathrm{m}}\right)$ and morphological (fine root distribution) adjustments were observed for $H$. rhamnoides and $P$. davidiana in the mixed plantation, respectively, to enlarge $\Psi_{\mathrm{pd}}-\Psi_{\mathrm{m}}$ and enhance the rainwater uptake and water consumption (Tables 1 and 2; Fig 7). Mixed afforestation also significantly decreased the deep soil water uptake proportion for both species (Table 3). 
Furthermore, mixed afforestation increased the total biomass of $H$. rhamnoides and $P$. davidiana that calculated through the allometric equation indicated in Zhou et al (2018) and Tang et al (2019) (Table S5). Thus, rainfall pulse sensitive species in pure plantation, and plant species in mixed plantation that can adopt physiological or morphological adjustment to enhance rainwater uptake and reduce excessive water uptake from deep soil layers, should be more considered for use in the studied region.

\section{Conclusions}

The influence of water sources and $\Psi_{\mathrm{pd}}-\Psi_{\mathrm{m}}$ on water consumption in response to rainfall pulse was determined for $H$. rhamnoides and $P$. davidiana in the semiarid Loess Plateau region. In pure plantations, the $\mathrm{SF}_{\mathrm{R}}$ was significantly influenced by RUP and $\Psi_{\mathrm{pd}}-\Psi_{\mathrm{m}}$ for $H$. rhamnoides, but the $\mathrm{SF} F_{\mathrm{R}}$ was only significantly influenced by $\Psi_{\mathrm{pd}}-\Psi_{\mathrm{m}}$ for $P$. davidiana. Meanwhile, the lower value $\Psi_{\mathrm{pd}}-\Psi_{\mathrm{m}}$ was consistent with the high $\mathrm{SF}_{\mathrm{R}}$ for $H$. rhamnoides, and the higher value $\Psi_{\mathrm{pd}}-\Psi_{\mathrm{m}}$ was consistent with the low $\mathrm{SF}_{\mathrm{R}}$ for $P$. davidiana, in response to rainfall pulses. Thus, $H$. rhamnoides and $P$. davidiana exhibited sensitive and insensitive response to rainfall pulses, respectively. Furthermore, mixed afforestation enhanced the rainwater uptake and water consumption for both species. Significantly lower plant $\Psi_{\mathrm{m}}$ and increased fine root surface area were adopted by $H$. rhamnoides and P. davidiana in the mixed plantation, respectively, to enlarge $\Psi_{\mathrm{pd}}-\Psi_{\mathrm{m}}$ and enhance rainwater uptake and decrease water source competition from the deep soil layer. The $\mathrm{SF}_{\mathrm{R}}$ was significantly influenced by RUP and $\Psi_{\mathrm{pd}}-\Psi_{\mathrm{m}}$ for both species in the mixed plantation, and rainwater uptake enhanced plant water consumption in the mixed plantation regardless of species sensitivity to rainfall pulses.

\section{Data availability}

The data that support the findings of this study are available from the corresponding author upon request.

\section{Author contribution}

YKT designed the study, performed the statistical analyses and wrote the original manuscript draft. 
LNW and YQY performed the experiments and collected the data. DXL collected the data.

\section{Declaration of Competing Interest}

The authors declare that they have no conflict of interest.

\section{Acknowledgement}

This work was supported by the National Natural Science Foundation of China (41977425), the National Key Research and Development Program of China (2017YFA0604801).

\section{References}

Allen, R.G., Periera, L.S., Raes, D., and Smith, M.: Crop evapotranspiration: Guidelines for Computing

Berkelhammer, M., Still, C., Ritter, F., Winnick, M., Anderson, L., Carroll, R., Carbone, M., and Williams, K. H.: Persistence and Plasticity in Conifer Water-Use Strategies, J Geophys Res-Biogeo, 125, 10.1029/2018JG004845, 2020.

Chen, Y. J., Cao, K. F., Schnitzer, S. A., Fan, Z. X., Zhang, J. L., and Bongers, F.: Water-use advantage for lianas over trees in tropical seasonal forests, New Phytol, 205, 128-136, 2015.

Cheng, X. L., An, S. Q., Li, B., Chen, J. Q., Lin, G. H., Liu, Y. H., Luo, Y. Q., and Liu, S. R.: Summer rain pulse size and rainwater uptake by three dominant desert plants in a desertified grassland ecosystem in northwestern China, Plant Ecol, 184, 1-12, 2006.

Dang, E., Jiang, Z,M., Li, R., Zhang, S.X., and Cai, J.: Relationship between hydraulic traits and refilling of embolism in the xylem of one-year-old twigs of six tree species, Scientia Silvae Sinicae, 53, 49-59, 10.11707/j.1001-7488, 2017. (In Chinese with English abstract)

De Guzman, M. E., Santiago, L. S., Schnitzer, S. A., and Alvarez-Cansino, L.: Trade-offs between water transport capacity and drought resistance in neotropical canopy liana and tree species, Tree Physiol, 37, 1404-1414, 2017. 
characteristics and climatic responses in three forest species in the semiarid Loess Plateau region of China, Agr Forest Meteorol, 151, 1-10, 2011.

Gebauer, R. L. E., and Ehleringer, J. R.: Water and nitrogen uptake patterns following moisture pulses in a cold desert community, Ecology, 81, 1415-1424, 2000.

Granier, A.: Evaluation of transpiration in a Douglas-fir stand by means of sap flow measurements, Tree Physioogy, 3, 309-320, 1987.

Grossiord, C., Sevanto, S., Dawson, T. E., Adams, H. D., Collins, A. D., Dickman, L. T., Newman, B. D., Stockton, E. A., and McDowell, N. G.: Warming combined with more extreme precipitation regimes modifies the water sources used by trees, New Phytol, 213, 584-596, 10.1111/nph.14192, 2017.

Hudson, P. J., Limousin, J. M., Krofcheck, D. J., Boutz, A. L., Pangle, R. E., Gehres, N., McDowell, N. G., and Pockman, W. T.: Impacts of long-term precipitation manipulation on hydraulic architecture and xylem anatomy of pinon and juniper in Southwest USA, Plant Cell Environ, 41, 421-435, 10.1111/pce.13109, 2018.

Iida, S., Shimizu, T., Tamai, K., Kabeya, N., Shimizu, A., Ito, E., Ohnuki, Y., Chann, S., and Keth, N.: measurements in a tropical dry deciduous forest, Ecohydrology, 9, 472-486, 10.1002/eco.1650, 2016. Jia, X. X., Zhao, C. L., Wang, Y. Q., Zhu, Y. J., Wei, X. R., and Shao, M. A.: Traditional dry soil layer index method overestimates soil desiccation severity following conversion of cropland into forest and grassland on China's Loess Plateau, Agr Ecosyst Environ, 291, Artn 106794,

Klein, T., Rotenberg, E., Cohen-Hilaleh, E., Raz-Yaseef, N., Tatarinov, F., Preisler, Y., Ogee, J., Cohen, S., and Yakir, D.: Quantifying transpirable soil water and its relations to tree water use dynamics in a water- limited pine forest, Ecohydrology, 7, 409-419, 10.1002/eco.1360, 2014.

Kumagai, T., and Porporato, A.: Strategies of a Bornean tropical rainforest water use as a function of rainfall regime: isohydric or anisohydric?, Plant Cell Environ, 35, 61-71,

10.1111/j.1365-3040.2011.02428.x, 2012.

Li, H. Q., Zhang, F. W., Zhu, J. B., Guo, X. W., Li, Y. K., Lin, L., Zhang, L. M., Yang, Y. S., Li, Y. N., 
Cao, G. M., Zhou, H. K., and Du, M. Y.: Precipitation rather than evapotranspiration determines the warm-season water supply in an alpine shrub and an alpine meadow, Agr Forest Meteorol, 300, ARTN 108318, 10.1016/j.agrformet.2021.108318, 2021.

Liu, Z. Q., Yu, X. X., and Jia, G. D.: Water uptake by coniferous and broad-leaved forest in a rocky mountainous area of northern China, Agr Forest Meteorol, 265, 381-389,

10.1016/j.agrformet.2018.11.036, 2019.

Meier, I. C., Knutzen, F., Eder, L. M., Muller-Haubold, H., Goebel, M. O., Bachmann, J., Hertel, D., and Leuschner, C.: The Deep Root System of Fagus sylvatica on Sandy Soil: Structure and Variation Across a Precipitation Gradient, Ecosystems, 21, 280-296, 10.1007/s10021-017-0148-6, 2018.

Mendham, D. S., White, D. A., Battaglia, M., McGrath, J. F., Short, T. M., Ogden, G. N., and Kinal, J.: Soil water depletion and replenishment during first- and early second-rotation Eucalyptus globulus plantations with deep soil profiles, Agr Forest Meteorol, 151, 1568-1579, 10.1016/j.agrformet.2011.06.014, 2011.

Moore, J. W., and Semmens, B. X.: Incorporating uncertainty and prior information into stable isotope mixing models, Ecol Lett, 11, 470-480, 10.1111/j.1461-0248.2008.01163.x, 2008.

Munoz-Villers, L. E., Geris, J., Alvarado-Barrientos, M. S., Holwerda, F., and Dawson, T.: Coffee and shade trees show complementary use of soil water in a traditional agroforestry ecosystem, Hydrol Earth Syst Sc, 24, 1649-1668, 10.5194/hess-24-1649-2020, 2020.

Nie, Y. P., Chen, H. S., Ding, Y. L., Zou, Q. Y., Ma, X. Y., and Wang, K. L.: Qualitative identification of hydrologically different water sources used by plants in rock-dominated environments, J Hydrol, 573, 386-394, 10.1016/j.jhydrol.2019.03.097, 2019.

Plaut, J. A., Wadsworth, W. D., Pangle, R., Yepez, E. A., McDowell, N. G., and Pockman, W. T.:

Reduced transpiration response to precipitation pulses precedes mortality in a pinon-juniper woodland subject to prolonged drought, New Phytol, 200, 375-387, 10.1111/nph.12392, 2013.

Silvertown, J., Araya, Y., and Gowing, D.: Hydrological niches in terrestrial plant communities: a review, J Ecol, 103, 93-108, 10.1111/1365-2745.12332, 2015.

Song, X. P., Hansen, M. C., Stehman, S. V., Potapov, P. V., Tyukavina, A., Vermote, E. F., and 
Townshend, J. R.: Global land change from 1982 to 2016, Nature, 560, 639,

10.1038/s41586-018-0411-9, 2018.

Stahl, C., Herault, B., Rossi, V., Burban, B., Brechet, C., and Bonal, D.: Depth of soil water uptake by tropical rainforest trees during dry periods: does tree dimension matter ?, Oecologia, 173, 1191-1201, 10.1007/s00442-013-2724-6, 2013.

Steppe, K., De Pauw, D. J. W., Doody, T. M., and Teskey, R. O.: A comparison of sap flux density using thermal dissipation, heat pulse velocity and heat field deformation methods, Agr Forest Meteorol, 150, 1046-1056, 10.1016/j.agrformet.2010.04.004, 2010.

Swaffer, B. A., Holland, K. L., Doody, T. M., Li, C., and Hutson, J.: Water use strategies of two co-occurring tree species in a semi-arid karst environment, Hydrol Process, 28, 2003-2017, 10.1002/hyp.9739, 2014.

Tang, Y. K., Wu, X., Chen, Y. M., Wen, J., Xie, Y. L., and Lu, S. B.: Water use strategies for two dominant tree species in pure and mixed plantations of the semiarid Chinese Loess Plateau, Ecohydrology, 11, Artn E1943, 10.1002/Eco.1943, 2018.

Tang, Y. K., Wu, X., Chen, C., Jia, C., and Chen, Y. M.: Water source partitioning and nitrogen facilitation promote coexistence of nitrogen-fixing and neighbor species in mixed plantations in the semiarid Loess Plateau, Plant Soil, 445, 289-305, 10.1007/s11104-019-04301-9, 2019.

Tfwala, C. M., van Rensburg, L. D., Bello, Z. A., and Zietsman, P. C.: Transpiration dynamics and water sources for selected indigenous trees under varying soil water content, Agr Forest Meteorol, 275, 296-304, 10.1016/j.agrformet.2019.05.030, 2019.

Wang, J., Fu, B. J., Wang, L. X., Lu, N., and Li, J. Y.: Water use characteristics of the common tree species in different plantation types in the Loess Plateau of China, Agr Forest Meteorol, 288, ARTN 108020, 10.1016/j.agrformet.2020.108020, 2020.

West, A. G., Hultine, K. R., Jackson, T. L., and Ehleringer, J. R.: Differential summer water use by Pinus edulis and Juniperus osteosperma reflects contrasting hydraulic characteristics, Tree Physiol, 27, 1711-1720, 10.1093/treephys/27.12.1711, 2007.

West, A. G., Dawson, T. E., February, E. C., Midgley, G. F., Bond, W. J., and Aston, T. L.: Diverse 
functional responses to drought in a Mediterranean-type shrubland in South Africa, New Phytol, 195, 396-407, 10.1111/j.1469-8137.2012.04170.x, 2012.

Wu, W. J., Li, H. J., Feng, H., Si, B. C., Chen, G. J., Meng, T. F., Li, Y., and Siddique, K. H. M.: forest (Robinia pseudoacacia) on the Loess Plateau after about 15 years of water depletion in deep soil, Agr Forest Meteorol, 297, ARTN 108244, 10.1016/j.agrformet.2020.108244, 2021.

Xu, Q., Liu, S. R., Wan, X. C., Jiang, C. Q., Song, X. F., and Wang, J. X.: Effects of rainfall on soil moisture and water movement in a subalpine dark coniferous forest in southwestern China, Hydrol Process, 26, 3800-3809, 10.1002/hyp.8400, 2012.

Yang, B., Wen, X. F., and Sun, X. M.: Seasonal variations in depth of water uptake for a subtropical coniferous plantation subjected to drought in an East Asian monsoon region, Agr Forest Meteorol, 201, 218-228, 10.1016/j.agrformet.2014.11.020, 2015.

Yang, B., Meng, X. J., Singh, A. K., Wang, P. Y., Song, L., Zakari, S., and Liu, W. J.: Intercrops improve surface water availability in rubber-based agroforestry systems, Agr Ecosyst Environ, 298, Artn 106937, 10.1016/J.Agee.2020.106937, 2020.

Zhang, C. C., Li, X. Y., Wang, Y., Wu, H. W., Wang, P., Li, W., Bai, Y., Li, E. G., Wang, S., Miao, C. Y., and Wu, X. C.: Responses of two desert shrubs to simulated rainfall pulses in an arid environment, northwestern China, Plant Soil, 435, 239-255, 10.1007/s11104-018-3892-2, 2019.

Zhang, H. D., Wei, W., Chen, L. D., and Yang, L.: Evaluating canopy transpiration and water use of two typical planted tree species in the dryland Loess Plateau of China, Ecohydrology, 10, Artn E1830, 10.1002/Eco.1830, 2017.

Zhang, H.X., L, S., Zhang, S.X., Xiong, X.Y., and Cai, J.: elationships between xylem vessel structure and embolism vulnerability in four Populus clones, Scientia Silvae Sinicae, 49, 54-61, 10.11707 / j.1001-7488.20130508. (In Chinese with English abstract)

Zhao, W. Z., and Liu, B.: The response of sap flow in shrubs to rainfall pulses in the desert region of China, Agr Forest Meteorol, 150, 1297-1306, 10.1016/j.agrformet.2010.05.012, 2010.

Zhao, Y., Wang, L., Knighton, J., Evaristo, J., and Wassen, M.: Contrasting adaptive strategies by 
https://doi.org/10.5194/hess-2021-351

Preprint. Discussion started: 30 August 2021

(C) Author(s) 2021. CC BY 4.0 License.

Caragana korshinskii and Salix psammophila in a semiarid revegetated ecosystem, Agr Forest Meteorol,

665

300, ARTN 108323,10.1016/j.agrformet.2021.108323, 2021.

Zhou, G.Y., Yin, G.C., Tang, X.L., Wen, Z.D., Liu, C.P., Kuang, Y.W., and Wang, W.T.: Carbon reserves

in forest ecosystems of China: Biomass allometric equation. Science Press, Beijing, China, 44-54, 2018.

(In Chinese). 